\title{
Gestão escolar e parceiros - elementos imprescindíveis na promoção da paz no ambiente escolar, com vistas a aprendizagem
}

\author{
Genilda Alves Nascimento Melo \\ Mestre em Supervisão e Formação de Formadores (ISCE)- Ramada, Portugal \\ Professora da Educação Básica \\ $凶$ genilda2010@gmail.com \\ Andréia Quinto dos Santos \\ Mestra em Educação Científica e formação de professores (UESB) - Bahia, Brasil \\ Professora da Educação Básica \\ 凶andreia.quinto@hotmail.com \\ Célia Jesus dos Santos Silva \\ Mestra em Letras (UESB) - Bahia, Brasil \\ Professora da Educação Básica \\ $\bowtie$ celiaflorzinha@gmail.com
}

Recebido em 14 de março de 2019

Aceito em 17 de junho de 2019

\section{Resumo:}

Esta pesquisa se propõe discutir como o ambiente escolar influencia na aprendizagem do aluno, qual responsabilidade da gestão escolar, em parceria com a comunidade escolar, para transformar o ambiente escolar na cultura de paz, pois que a escola precisa cuidar da integridade física e mental dos estudantes. A ideia de falar sobre esse tema surgiu, quando um aluno foi assassinado em frente à escola. Portanto, será discutida a paz sobre dois aspectos: como ausência de guerra; bem como, comportamentos e atitudes que respeitam a vida, a dignidade, os direitos humanos, como um conjunto de valores indissociáveis. Alinhado ao conceito negativo de paz aparece a violência direta - agressão que uma pessoa deflagra contra a outra ou outras; a violência estrutural - aquela que não se consegue identificar o sujeito ou sujeitos que a comete, visto que está estritamente ligada à injustiça social. O clima de violência na escola, além de incidir no desempenho negativo dos resultados de aprendizagem, intervém na atuação técnico-pedagógica dos profissionais da educação, como também, na visão física da unidade escolar; assim, é preciso apresentar a maneira pela qual vários órgãos de apoio (Polícia, Conselho Tutelar, Ministério Público, Clínica de Atendimento Psicossomático, Hospitais, entre outros) à escola podem contribuir para o apaziguamento. Esta pesquisa possibilitou a investigação colaborativa entre os professores - pesquisadores e a comunidade escolar; onde através de uma entrevista semiestruturada, opinaram sobre as mudanças que deveriam acontecer dentro da unidade escolar, para enfrentamento e resolução do problema imediato, no Colégio Estadual Sesquicentenário, em Itabuna, na Bahia. A escola, como sede da produção de conhecimento, deve empreender parcerias com a comunidade regional, para que se torne ambiente de paz e apaziguador, com segurança, a fim de que os alunos tenham o direito de aprender garantido, sendo a aprendizagem um princípio fundamental para a escola e para o aluno.

Palavras - chaves: Escola, Gestão e parceiros, Paz, Aprendizagem. 


\title{
School management and partners - essential elements in promoting peace in the school environment, with a view to learning
}

\begin{abstract}
:
This research proposes to discuss how the school environment influences student learning, what responsibility of school management, in partnership with the school community, to transform the school environment into a culture of peace, since the school needs to take care of the physical and mental integrity of the students. The idea of talking about it came when a student was murdered in front of the school. Therefore, peace will be discussed on two aspects: as absence of war; as well as behaviors and attitudes that respect life, dignity and human rights, as a set of inseparable values. Aligned to the negative concept of peace appears direct violence aggression that one person deflagrates against the other or others; structural violence - one that can not identify the subject or subjects who commit it, since it is strictly linked to social injustice. The climate of violence in the school, besides affecting the negative performance of the learning outcomes, intervenes in the technical-pedagogical performance of the education professionals, as well as in the physical vision of the school unit; thus, it is necessary to present the way in which various support organs (Police, Guardianship Council, Public Prosecutor's Office, Psychosomatic Care Clinic, Hospitals, among others) to the school can contribute to appeasement. This research hat enabled collaborative investigation between teachers - researchers and the school community; where through a semistructured interview, they expressed their opinion about the changes that should take place within the school unit, in order to confront and solve the immediate problem, at Sesquicentenário State College, in Itabuna, Bahia. This way the school, as the headquarters for the production of knowledge, must enter into partnerships with the regional community, so that it can become a peaceful and secure environment, so that students have the right to learn guaranteed, learning being a fundamental principle to the school and to the student.
\end{abstract}

Key - words: School, Management and partners, Peace, Learning.

\section{Gestión escolar y socios - elementos imprescindibles en la promoción de la paz en el ambiente escolar, con miras al aprendizaje}

\section{Resumen:}

Esta investigación se propone discutir cómo el ambiente escolar influye en el aprendizaje del alumno, cuál responsabilidad de la gestión escolar, en asociación con la comunidad escolar, para transformar el ambiente escolar en la cultura de paz, pues la escuela necesita cuidar de la integridad física y mental de los padres estudiantes. La idea de hablar sobre este tema surgió cuando un alumno fue asesinado frente a la escuela. Por lo tanto, se discutirá la paz sobre dos aspectos: como ausencia de guerra; así como comportamientos y actitudes que respetan la vida, la dignidad, los derechos humanos, como un conjunto de valores indisociables. Alineado al concepto negativo de paz aparece la violencia directa - agresión que una persona deflagra contra la otra u otras; la violencia estructural -la que no se puede identificar al sujeto o sujetos que la comete, ya que está estrictamente ligada a la injusticia social. El clima de violencia en la escuela, además de incidir en el desempeño negativo de los resultados de aprendizaje, interviene en la actuación técnico-pedagógica de los profesionales de la educación, así como en la visión física de la unidad escolar; es necesario presentar la mane ra en que varios órganos de apoyo (Policía, Consejo Tutelar, Ministerio Público, Clínica de Atención Psicosomática, Hospitales, entre otros) a la escuela pueden contribuir al apaciguamiento. La averiguación que posibilitó la investigación colaborativa entre los profesores - investigadores y la comunidad escolar; donde a través de una entrevista semiestructurada, opinaron sobre los cambios que debían ocurrir dentro de la unidad escolar, para enfrentamiento y resolución del problema inmediato, en el Colegio Estadual Sesquicentenario, en Itabuna, en Bahía. De esta forma, la escuela, como sede de la producción de conocimiento, debe emprender alianzas con la comunidad regional, para que se convierta en un ambiente de paz y apaciguador, con seguridad, a fin de que los alumnos tengan el derecho de aprender garantizado, siendo el aprendizaje un principio fundamental para la escuela y para el alumno.

Palabras claves: Escuela, Gestión y socios, Paz, Aprendizaje. 
Gestão escolar e parceiros - elementos imprescindíveis na

promoção da paz no ambiente escolar, com vistas a aprendizagem

\section{INTRODUÇÃO}

A violência na escola tem provocado uma série de questões reflexivas sobre o papel da gestão, pois o ambiente escolar tem sido local de manifestações agressivas - depredações do patrimônio físico; agressões verbais e até violência física contra alunos, entre eles; aluno contra professor; fora da escola, brigas por motivos frívolos. Este trabalho, portanto, teve início com a mudança de rotina da escola: assassinato de um aluno, por um grupo de risco, na porta da escola.

A pesquisa está dividida nos seguintes momentos: primeira abordagem será os múltiplos olhares sobre a paz - conceitos positivos e negativos, alinhados à violência; segundo momento, é apresentado uma abordagem conceitual sobre a aprendizagem e a paz; seguindo, tem -se participação da comunidade escolar na promoção da paz, elemento indispensável na promoção da paz; o Colegiado Escolar e a construção da paz na escola, segmento gerenciador das ações educativas; o papel da Gestão Escolar na promoção da paz administrar e gerar condições favoráveis; Família e Escola pela paz no ambiente escolar contribuir, monitorar as ações dos filhos.

Os resultados da pesquisa trazem a voz dos professores e dos alunos; mostram análise e cruzamento dos dados; fazem a conclusão das descobertas da pesquisa.

\section{OS MÚLTIPLOS OLHARES SOBRE A PAZ}

O conceito da palavra paz, utilizado pela cultura ocidental, conforme Carlos Callado (2004) traz um histórico etimológico de dois termos: eirene (grego) e pax (romano). Eirene é identificado como a busca da perfeição na harmonia mental e na tranquilidade interior. Já a Pax estabelecia a ordem e o respeito às leis romanas. Este mesmo autor contrapõe esses conceitos afirmando que a principal diferença entre eirene grega e a pax romana é que a primeira buscava um equilíbrio nas relações entre os diferentes centros da atividade sócio política grega, enquanto que a segunda se desenvolveu num marco imperialista e centralizado, cujo objetivo primeiro era privilegiar Roma, centro da estrutura política. Dessa forma, a paz romana foi uma definição de paz no sentido de ausência de violência segundo a lei, mas não no sentido de justiça, prosperidade, reciprocidade e igualdade para todos. No 
entanto, a segunda diferença entre esses conceitos é que havia, junto com a manutenção da lei e da ordem interior, uma preparação militar orientada a ampliar ou defender o Império de ameaças exteriores. 0 mundo ocidental universalizou a união entre esses dois conceitos e transformou em um estado negativo o pensar a paz como ausência de violência, guerras e conflitos.

Marcelo Pereira (2015) mostra a política na produção e mediação da paz. Entretanto, retoma a visão judaica sobre a paz: a experiência do homem com Deus o fará manter um compromisso social com o outro, respeitando os direitos e espaços, a convivência saudável.

Raquel Cabral et al. (2014) distinguem a violência direta da violência estrutural. Eles atribuem a violência direta ao conceito de agressão direta causada por pessoas que cometem atos de destruição contra as outras; sendo que a violência estrutural é a em que não é possível identificar o sujeito ou os sujeitos que cometem. Este último, estritamente ligado à injustiça social, pois o indivíduo para sair da violência estrutural pratica a ação direta contra o outro, ideia que veio redimensionar os conceitos de violência e paz. A Organização Mundial das Nações Unidas traduz o conceito de paz em comportamentos e atitudes que respeitam a vida, a dignidade, os direitos humanos, como um conjunto de valores indissociáveis. Dessa forma, Callado (2004) diz que violência seria a causa da diferença entre o que uma pessoa poderia ser, mas não é, devido à situação que padece, à causa que impede o desenvolvimento de todas as potencialidades dos seres ou dos grupos humanos. Fechando esses conceitos ele diz que,

Definitivamente, uma concepção positiva da paz implica um processo dinâmico, orientado não só para a ausência de condições e circunstâncias desejadas, mas que busque a presença das condições e circunstâncias desejadas. A paz converte-se, assim, num dos valores máximos da existência humana e, como tal, afeta todas as dimensões da vida: interpessoal, intergrupal, nacional, internacional e mundial. Deixa de ser utopia irrealizável, um ideal inalcançável, para converter-se num processo contínuo e acessível, baseado na justiça, em que a cooperação, o mútuo entendimento e a confiança em todos os níveis assentem as bases das relações social, do qual, todos, podemos participar e que, ao qual, todos podemos contribuir. (CALLADO, 2004, p.23)

Outro assunto que passou por uma releitura de conceito foi o conflito. $\mathrm{Na}$ perspectiva da paz positiva, houve a distinção entre a necessidade do conflito e ter o conflito como uma realidade não desejável. Sob esse ponto de vista, o conflito é um processo comum a toda sociedade e um fenômeno imprescindível à vida humana, podendo ser um 
Gestão escolar e parceiros - elementos imprescindíveis na

promoção da paz no ambiente escolar, com vistas a aprendizagem

fator de caráter prático positivo nas mudanças e nas relações ou motivo para destruição, de acordo com a maneira que se aplica. O conflito passa a ser um fator importante na transformação da sociedade. Argumentando, Gilberto de Oliveira (2017) afirma que o conflito passa a ser paradoxal em que as duas partes opostas cooperam em um processo de busca intelectual e emocional, para transformar o problema da incompatibilidade de metas na procura de uma meta comum. O conflito deixa de ser, então, um processo de oposição em que uma das partes ganha e a outra perde, impondo à primeira sua postura sobre a segunda, para se converter em um processo de cooperação, no qual, ambas as partes tratam de encontrar uma solução comum que seja aceitável e proveitosa para todos.

Assim, fica absolutamente sem legitimidade o uso de qualquer tipo de violência e, neste sentido, a não - violência e a cultura da paz são sinônimas que mostram a única resposta possível à concepção de paz positiva.

\section{APRENDIZAGEM - BREVES CONCEITOS}

Entender como o homem aprende sempre foi um desafio para estudiosos desta área. Sabe-se que há diferentes processos de aprendizagem. Mas o que é mesmo aprendizagem? Jerome Bruner (1976) apresenta a aprendizagem como uma mobilidade do potencial cognitivo, onde as informações são processadas e simplificadas, à medida que o sujeito se relaciona com o mundo real. Portanto, aprender é elaborar uma representação pessoal da realidade a partir de experimentações e conhecimentos previamente adquiridos. César Coll (1994) afirma que, para que isto aconteça é preciso duas condições: o conteúdo ser significativo e o aluno está motivado. Sacristán \& Goméz (2000) conferem a aprendizagem a ideia de um processo de doação de sentido, de significado, às situações em que o indivíduo se encontra, que sob as manifestações observáveis se desenvolvem processos de discernimento e de busca intencional dos objetivos e metas.

A aprendizagem é definida por Celso Antunes (2002) como uma mudança relativamente permanente no comportamento que resulta em experiência. Dessa forma, mostra a importância do ambiente para a aprendizagem, visto que esta só poderá consolidar - se através da adequação ao meio ambiente; de igual modo, a maturação para que isto aconteça. 
Portanto a aprendizagem, jamais ocorre antes que algumas aptidões motoras, neurológicas ou sensoriais estejam aptas para isto. Percebe - se a importância da maturação na programação genética de todo bebê. É possível sintetizar o esquema dizendo que a maturação prepara o corpo e desperta a habilidade, e que o ambiente e experiência consolidam as primeiras formas de aprendizagem.

Alguns estudiosos apresentam diversas maneiras da aprendizagem ocorrer. Por formação de hábito, quando há o processo de exposição repetida a um estímulo. Este procedimento está associado ao desenvolvimento do ser humano. A ausência do hábito poderá criar transtornos no desenvolvimento da pessoa. Um dos defensores desta ideia é Henry Gleitman (1999). A aprendizagem acontecerá também por condicionamento clássico. Ivan Pavlov (1904) descobriu que há aprendizagem, quando uma pessoa dá resposta a um estímulo que não era desencadeado originalmente, mas que depois de repetidas vezes associado, desencadeia a resposta. Ainda o aprender acontece por esforço positivo e negativo. $O$ pesquisador defende a ideia e que todas as vezes que há prêmio ou punição o ser humano aprende, pois, muda de comportamento.

Albert Brandura et al (2008) argumentam que os pais desempenham um papel, ainda que não exclusivo, no funcionamento de modelos; pois geralmente é a partir deles que a criança aprende a fala; desenvolve o senso moral; trabalha sua raiva e suas frustações; aprende com o meio social e desenvolve a autoestima, mas atemoriza, ao perceber o papel que a televisão exerce, a cada dia sobre as famílias, quando oferece modelos nem sempre semelhantes a ideia de um futuro melhor.

Excepcionalmente, Jean Piaget (1959) surpreendeu o mundo, trazendo uma nova leitura sobre a aprendizagem. Este assegurou que aprendizagem acontece em diversos momentos na vida do ser humano, de forma organizada e hierárquica, chamando - os de estágios de desenvolvimento cognitivo. Em cada uma dessas fases, se constrói um tipo de aprendizagem, onde um depende do outro. Nesses esquemas, as representações básicas das estruturas cognitivas, são a base de transformação de concreto ao abstrato. $O$ ser humano terá um desenvolvimento completo para aprendizado, se persistir na construção do conhecimento sem transpor nenhuma das etapas.

Lev Vygotsky (1984) postulou que a aprendizagem sempre inclui relações entre pessoas. Ele defende a ideia de que o ser humano não nasce com um sistema interno pronto, que se atualiza, à medida que a pessoa cresce. Mas o desenvolvimento é pensado como um 
Gestão escolar e parceiros - elementos imprescindíveis na

promoção da paz no ambiente escolar, com vistas a aprendizagem

processo, formado pela maturação do organismo, a relação com a cultura produzida pela humanidade e as interações sociais resultantes da aprendizagem.

Mais tarde, Howard Gardner (1999) mostra que a aprendizagem está centrada de forma horizontal, mas verticalmente organizada, e que, ao invés de haver uma faculdade mental geral, como a memória talvez exista formas independentes de percepção, memória e aprendizado, em cada área de domínio; com possíveis semelhanças entre as áreas, mas não necessariamente uma relação direta. Mostra que cada sujeito tem micro campos organizados e sintonizados entre eles, que de acordo com a ênfase que a cultura lhe dá, o indivíduo terá mais domínio do conhecimento em cada área: seja espacial, lógico matemática, linguística, musical, corporal - cinestésica, existencial ou relacional. Isto ele chamou de inteligências múltiplas. Dessa forma, a aprendizagem ocorre em função de especificidades da inteligência, que se referem a capacidades mais ou menos desenvolvidas do sujeito. Portanto, quanto mais estímulos variados, que potencializem as inteligências, recebidas pela criança, mais possibilidades terá de um aprendizado; pois nos procedimentos didáticos - pedagógicos, é preciso identificar as inteligências mais definidas, em cada aprendiz e procurar analisá - las para atingir o objetivo final, que é o aprendizado.

Em se tratando de conhecimento escolarizado, essencialmente importante a presença e o acompanhamento do professor, em cada uma dessas etapas. Para melhor compreender o fazer docente, faz - se necessário, entender a forma como cada uma dessas etapas conhecimento acontece.

\section{A PARTICIPAÇÃO DA COMUNIDADE ESCOLAR NA PROMOÇÃO DA PAZ}

Nos últimos anos, a escola foi invadida por comportamentos agressivos, em que não há mais respeito ao outro. Adolescentes impõem sua forma de ser e de agir em detrimento às normas de convivência do ambiente escolar. Xinga, destrata, agride física e psicologicamente o colega, o assistente da direção, o professor, o gestor (a) escolar, coordenador (a) e demais pessoas envolvidas no processo do ensino. 0 "empoderamento" trazido pelo uso de drogas ilícitas; a disputa entre as facções criminosas vem centrando espaço dentro das unidades escolares, onde adolescentes participam de forma direta

\footnotetext{
${ }^{1}$ Vocábulo usado para expressar o grau de emancipação do adolescente, subjugando demais pessoas.
} 
(muitos são "chefe de boca de fumo"); outros atuam de forma indireta (são os “aviõezinhos"). 0 resultado de algum desentendimento lá fora, culmina no encontro dentro da escola, gerando grande conflito e até morte dentro da unidade escolar.

Assim, a escola traz sinais visíveis da crise de competências, já que sozinha não conseguirá resolver situações dizes respeito a sociedade como um todo. Neste postulado está implícita a ideia de mudança dessa instituição que tem histórico de desmando e hierarquias. É preciso buscar aliados em seu entorno, as "redes de proteção", pois que, para Michele Marchesan et al. (2017) a escola já não é mais compatível com as subjetividades dos seus alunos. Portanto, a ação grupal precisa ser estabelecida, a comunidade e suas representações deverão assumir a cogestão na escola.

\section{O COLEGIADO ESCOLAR E A CONSTRUÇÃO DA PAZ NA ESCOLA}

Oferecer a educação escolarizada de qualidade, como contribuição no processo da formação humana, é a função principal da escola, visto que ela deve garantir a instrução aos alunos, "contribuindo para que se tornem sujeitos, isto é, autores e senhores de suas vidas. Isto significa, criar oportunidades para que eles decidam, pensem, tornem - se livres e responsáveis, autônomos, emancipados" (SEC-BA, 2017, p. 2)

Cabe à escola respeitar a história de vida do estudante, a visão de mundo que ele traz, a sensibilidade, os valores construídos na convivência do grupo. Quando isto não acontece, a escola deixa de participar do processo de formação humana e estimula a violência simbólica e desta a violência física. Por isso, é preciso que todos participantes da escola estejam atentos e, em especial, o Colegiado Escolar. Este é um dos órgãos mais importantes na construção da gestão democrática. É ele o responsável pelo gerenciamento da prática educativa, já que a função prioritária desse órgão é a político - pedagógico. Assim, o Colegiado Escolar deverá, junto com parceiros, criar instrumentos norteadores do processo educativo, que visem minimizar as diferenças no trato dos resultados e ao mesmo tempo, respeitem as diferenças individuais, no caminhar para esses resultados, visto que, a

\footnotetext{
${ }^{2}$ Expressão que indica a hierarquia dentro do tráfico - quem dá ordens.

3 Última instância - o serviçal: leva a droga e traz o dinheiro para o chefe (fielmente).

${ }^{4}$ Parceiros protetivos de apoio à Escola Pública - instituições governamentais ou não que atuam em questões sociais de alta complexidade, definindo planos na resolução de problemas com crianças e adolescentes em situação de risco.
} 
escola reproduz tanto as relações econômicas, quanto as relações sociais que ocorrem na sociedade, com todas as suas contradições. Nelas estão presentes os diversos interesses dos grupos sociais, que evidenciam conflitos. Visto que, quando os conflitos ocorrem na escola, há tendências para ignorá - los, outras vezes desconsiderá - los, como ainda reduzi - los. 0 que demonstra desrespeito para com o outro.

Figura 1 - A função do Colegiado Escolar

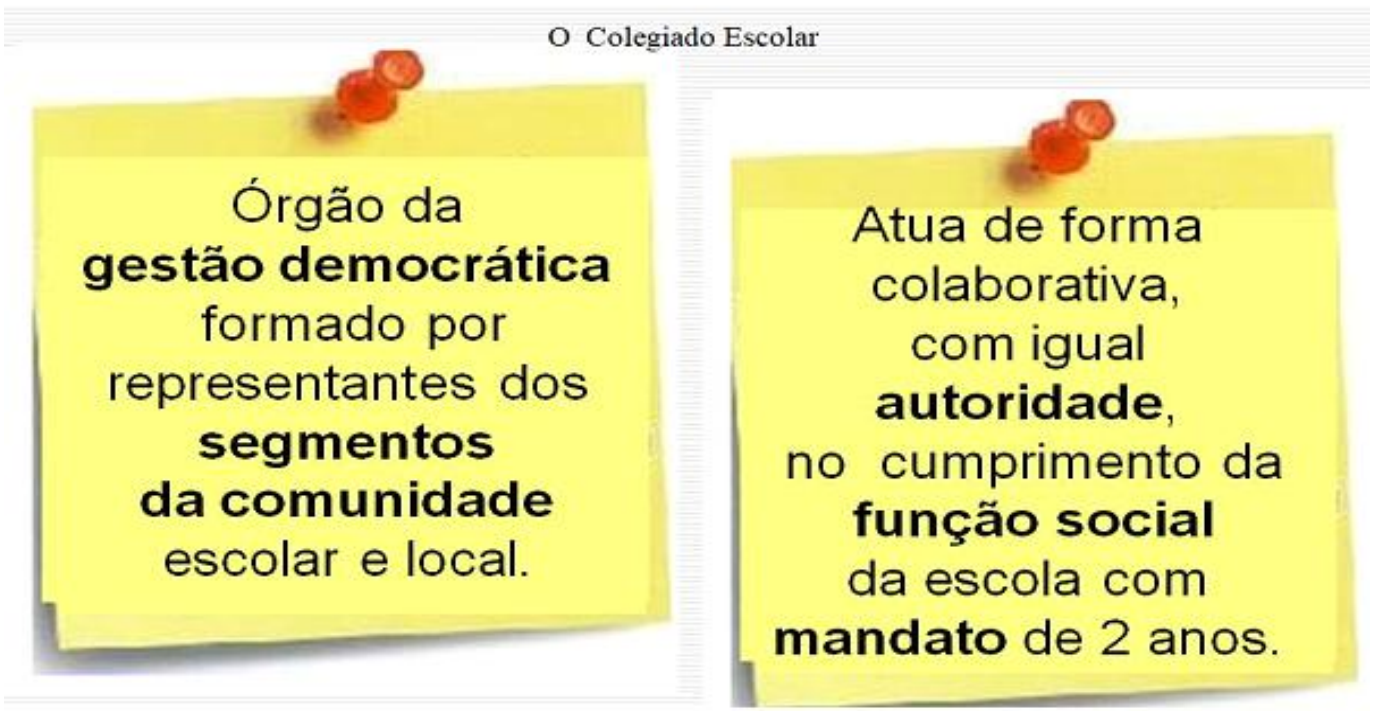

Fonte: Manual do Colegiado Escolar, MEC, 2010.

Como elemento chave da promoção da paz na escola, o Colegiado Escolar deve monitorar ações da escola que venham causar qualquer forma de exclusão, pois no contexto social está impregnada a ideia de exclusão e dessa maneira, a escola tende a reproduzir interesses e práticas sociais de representações majoritárias, de forma a contribuir para o aumento das injustiças e desigualdades sociais. Nesta perspectiva, a escola não ensina o que é necessário e significativo, não respeita nem integra o saber e a cultura da comunidade, é incapaz de educar. Sugere que a instituição escola tem preconceitos étnicos, raciais, religiosos e de classe que criam segregam, favorecendo um grupo ou outro; desfavorecendo a muitos outros. Com a prática não inclusiva, deflagra a violência, onde grupo excluídos tentam impor frente a situações eliminatórias. 


\section{O PAPEL DA GESTÃO ESCOLAR NA PROMOÇÃO DA PAZ}

Ao Gestor Escolar cabe a função de administrar os desmandos resultantes da violência instalada na escola, mas um dos grandes desafios da gestão escolar é criar um clima que favoreça a aprendizagem. Pesquisas realizadas em quatorze capitais do país, em escolas públicas e particulares revelam o impacto da violência sobre o ambiente escolar, fato que dificulta o aprender, aumenta a falta dos alunos e piora a qualidade do ensino. É também um fator que inviabiliza as relações interpessoais, incisivo na qualidade do trabalho do professor e que reflete no resultado geral da escola, haja vista,

O clima de violência, além de influir na qualidade do ensino, no desempenho escolar dos alunos e no desempenho profissional do corpo técnico - pedagógico, também incide sobre a percepção dos alunos a respeito do espaço físico da escola, da gestão e dos próprios colegas. Constata - se que um ambiente desfavorável contribui para o esgarçamento das relações entre os atores da escola.

Para Sobreiro e Estrada (2016) é preciso que a gestão busque, em colaboração com a equipe de trabalho, estratégias de observação do entorno da escola, do ambiente escolar, da interlocução entre escola - família - comunidade, a prática efetiva de ações, que visem dirimir os conflitos negativos, organize projetos voltados para o aluno, de forma a criar laços e condutas de pertencimento do jovem na relação com a escola; fomentar trabalhos voltado para a promoção da identidade étnica, observando os direitos a pluralidade cultural dos alunos; agir de forma dialogal com seus pares, pois é condição sine qua non para atrair os parceiros de trabalho.

Valorizar a participação ativa dos profissionais que atuam na unidade escolar é uma estratégia com resultados positivos, testados por algumas escolas, onde o índice de violência foi reduzido. É possível observar que a apreciação respeitosa sobre o trabalho do outro pode desencadear uma série de transformações nos comportamentos e modos de agir dos adolescente e jovens; como ainda, dos professores, apreendido como reconhecimento social. Da mesma maneira, manter o espaço físico limpo, adequado e ordenado é indício de reconhecimento. As instalações falam do sentido e importância dados a educação.

A competência coletiva é uma palavra de ordem na gestão escolar. Dentro da escola, cada segmento deve ter a clara função a ser exercida, mas ao mesmo tempo, o cooperativo deve ser estabelecido, visto que na ausência de um componente, o trabalho segue rotina organizada. Sendo assim, as práticas de trabalho coletivo têm resultados positivos, já que o 
Gestão escolar e parceiros - elementos imprescindíveis na

promoção da paz no ambiente escolar, com vistas a aprendizagem

rumo da escola é responsabilidade de todos. Para tanto, é preciso que se crie um projeto educativo de valorização social, sob o ponto de vista plural e da prática democrática. Indispensável, portanto, uma direção efetiva que possa coordenar e dar andamento às ações, mediando os conflitos e interesses resultados desse processo.

\section{FAMÍLIA E ESCOLA PELA PAZ NO AMBIENTE ESCOLAR}

A relação escola/família tem sido objeto de discussões em década de estudo. Por serem as duas instituições mais importantes na formação do sujeito, é preciso que caminhem em parceria; dialoguem; compartilhem dos mesmos objetivos. Ducemara Benato (2014) põe a escola como responsável ao chamamento da família, para que garanta a cooperação dos pais no envolvimento relacional, filosófico, político e pedagógico. Assim, para que a família entenda a linguagem da escola, é importante que os pais participem das atividades envolvidas pela escola e tenham consciência da educação que os filhos estão recebendo e passem a contribuir, mais efetivamente. Em razão de ter sido considerada, por muito tempo, como o único ambiente de formação, a escola ainda observa de forma tímida a parceria escola/família.

André de Oliveira (2015) mostra que a escola tem se defrontado com desencontros entre o seu papel e a realidade familiar. Ele atribui esse problema a mudanças no modelo de família. Assim, o reflexo das alterações social leva a escola a tomar uma postura diferente. 0 seu pensar em firmar parceria com a família e a comunidade local é um passo importante para a efetivação das ações pontuais de redução da violência em seu ambiente, posto que é da família que o aluno recebe as primeiras instruções. Os valores aprendidos no convívio familiar irão acompanhá-lo de forma mais duradoura do que os adquiridos na escola.

A instituição escolar é uma ponte entre a família e a sociedade; é a soma da cultura vivenciada na cidade, nas praças, na rua, na roda de amigos, nos meios de comunicação, na família, no trabalho, outros. Mas ao mesmo tempo representa a cultura formal - domínio dos pensamentos e dos conhecimentos. De acordo com Luana Santos e José Toniosso (2014),

A escola tem como função fazer com que o indivíduo seja capaz de resolver as diversas situações, de modo a desenvolver suas habilidades e competências para a aquisição dos variados conhecimentos, transpassando à mera aquisição de 
conteúdos programados, mas que leve em consideração a formação de um ser crítico/reflexivo, que saiba relacionar sua historicidade com o saber construído no decorrer de sua trajetória escolar. (SANTOS e TANIOSSO, 2014, p.11)

É imperativo que a escola conheça os novos princípios da família, seus medos, inseguranças, resistências e dificuldades, para então envolvê - la em objetivos que envolvem a comunidade escolar. Assim, a paz será estabelecida e a aprendizagem realizada.

\section{METODOLOGIA}

A presente investigação será realizada através de um diagnóstico sobre o pressuposto de violência escolar, em razão do assassinato de uma estudante na porta a unidade escolar; momento em que a comunidade escolar será ouvida e participará das discussões sobre os resultados obtidos, após análise dos dados, a fim de encontrar possíveis soluções, em caráter imediato.

Para efetivação deste trabalho, priorizou - se o método da Pesquisa - ação. Tanajura e Bezerra (2015) mostram que a pesquisa-ação envolve o pesquisador diretamente às pessoas que serão objeto de investigação. Assim, requer uma postura de autonomia do pesquisador, mas ao mesmo tempo, visa não "separar o pesquisador do pensamento e da ação, dos fatos e dos valores, evitando o seu afastamento da responsabilidade com as questões humanas." (p.17)

\section{Amostra}

A coleta de dados foi realizada no período entre 06 a 08 de julho de 2010, no Colégio Estadual Sesquicentenário, em Itabuna - BA, na modalidade entrevista semiestruturada, em amostra coletada entre trinta professores, abrangendo as três áreas do conhecimento: Linguagens, Códigos e suas Tecnologias, Ciências da Natureza, Matemática e suas Tecnologias e Ciências Humanas e suas Tecnologias. A pesquisa foi executada em horários de planejamento dos professores, junto com o articulador de área. Os profissionais que participaram da pesquisa tinham entre 05 a 30 anos de serviços na unidade escolar, lecionando em séries do Ensino Fundamental e no Ensino Médio, dos turnos matutino e 
vespertino. De igual modo, foram entrevistados noventa (90) alunos da quinta a oitava série do Ensino Fundamental e quarenta e dois (42) alunos do Ensino Médio.

Tabela 1- Descrição da amostra

\begin{tabular}{l|ll}
\hline Participantes da pesqui sa & Quantidade & Percentual \\
\hline \multirow{2}{*}{ Alunos } & 132 & \\
Pais & 58 & $48,8 \%$ \\
Professores & 80 & $21,98 \%$ \\
& & $29,62 \%$ \\
\hline
\end{tabular}

Fonte: Dados de análise da pesquisa.

Professores foram convidados a responder sobre a relação deles com os alunos; com os pais; com o corpo gestor da escola; se sentiam seguros, mesmo depois do assassinato do aluno frente à escola e quais medidas deveriam ser tomadas para garantir a segurança na escola. Os alunos foram motivados a responder sobre a relação professor/aluno; a comunicação deles com os pais; convidados a refletir se o fatídico corrido com o colega em frente à escola teria afetado o desempenho deles no resultado da aprendizagem.

\section{RESULTADOS / DISCUSSÕES}

A Pesquisa - ação trouxe maior envolvimento de professores, alunos e demais atores da comunidade escolar.

Na relação professor/aluno $80 \%$ dos pesquisados afirmaram ter bom relacionamento com o aluno; $15 \%$ apresentou regularidade na convivência em sala de aula, mas 5\% desses professores queixou não se relacionar bem com o aluno. No item relacionamento com a gestão escolar, $90 \%$ dos professores comunicaram, participar da gestão escolar; $10 \%$ fez restrição no relacionamento com a gestão. Já no sentido de segurança, após a morte do estudante na porta da escola, $80 \%$ dos entrevistados ainda se sentiam seguros em trabalhar 
na escola; entretanto, $20 \%$ estava temeroso, quanto ao desencadeamento de outros problemas, motivados pelo fatídico acontecimento. Entretanto foram sugeridas medidas de segurança, tais: instalação de câmeras para monitoramento; presença e revista de policiais dentro da unidade escolar; mais policiais na porta da escola; punição aos atos de violência; seminário sobre a temática com alunos e pais; fazer escolha de líderes; criar projeto para perpassar o ano letivo, cuidando do tema.

Gráfico 1- Nível de insegurança do professor após morte do estudante.

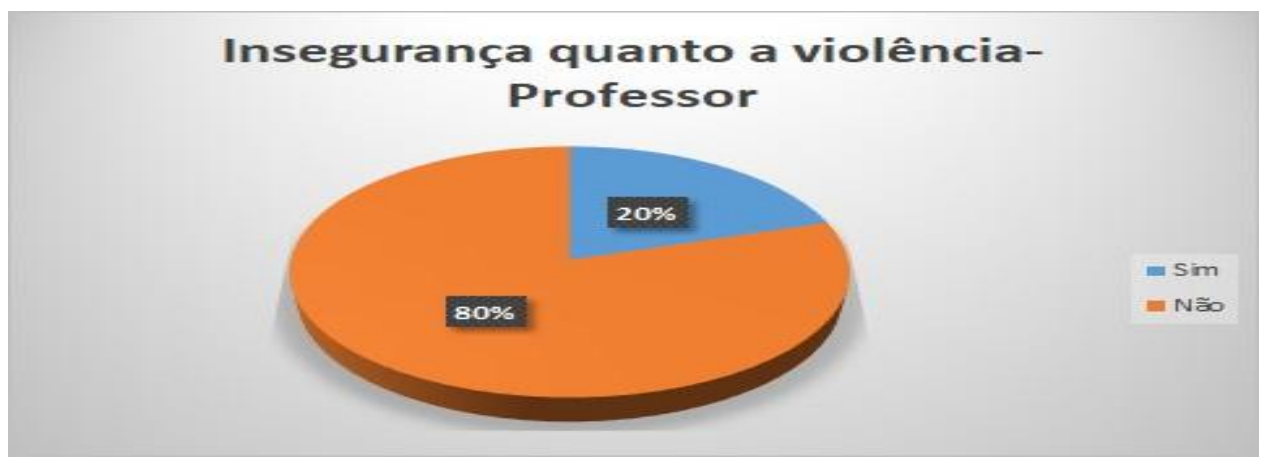

Fonte: Dados da pesquisa.

Os alunos responderam em $75 \%$ ter um bom relacionamento com o professor; $20 \%$ afirmou uma convivência regular com o professor e 5\% mostrou insatisfeito com o quadro docente da sala deles. No quesito comunicação com os pais $78 \%$ não se sentia à vontade para falar sobre os seus segredos aos pais; $22 \%$ tinha relação aberta com os pais em poder contar os seus problemas. Quando interrogado sobre em que a morte do colega em frente à escola refletia no resultado de aprendizagem, 85\% afirmou está preocupado com os fatos que poderiam ocorrer a partir daquela situação, fato que tirava a concentração deles. $15 \%$ dos entrevistados ainda não tinha parado para pensar sobre o assunto. 
Gestão escolar e parceiros - elementos imprescindíveis na

promoção da paz no ambiente escolar, com vistas a aprendizagem

Quadro 1- Responsabilidades na promoção da paz na escola.

\begin{tabular}{|c|c|c|c|}
\hline $\begin{array}{l}\text { Participantes da } \\
\text { pesquisa }\end{array}$ & $\begin{array}{c}\mathrm{N}^{\circ} \mathrm{de} \\
\text { entrevistados }\end{array}$ & Percentual & $\begin{array}{l}\text { Qual a responsabilidade de cada } \\
\text { segmento na promoção da paz na } \\
\text { escola? }\end{array}$ \\
\hline Alunos & 132 & $48,8 \%$ & $\begin{array}{l}\text { *Mudança de atitude; } \\
\text { *Empoderamento positivo; } \\
\text { *Valorizar a diversi dade. }\end{array}$ \\
\hline Pais & 80 & $21,48 \%$ & $\begin{array}{l}{ }^{*} \text { Caminhar em parceria; } \\
* \text { Dialogar sobre os problemas; }\end{array}$ \\
\hline & & & $\begin{array}{l}\text { *Participar das atividades } \\
\text { propostas. }\end{array}$ \\
\hline Professores & 58 & $29,62 \%$ & $\begin{array}{l}\text { *Respeitar a história e vida; os } \\
\text { valores e a visão de mundo do } \\
\text { aluno. }\end{array}$ \\
\hline
\end{tabular}

Fonte: Dados de análise da pesquisa.

Toledo et al (2014) apresentam a pesquisa-ação como investigação, intervenção e produção de saberes; um sistema metodológico aberto e dinâmico, já que combina instrumentos dialéticos e não dialéticos. Dessa forma, é possível planejar a melhora da prática $=>$ agir para implantar a melhora planejada $=>$ monitorar e descrever os efeitos da ação => avaliar os resultados da ação. Dessa forma, mesmo não tendo o resultado desastroso, mas uma perspectiva de medo entre a comunidade, a gestão e parceiros implementaram diversas ações para fortalecer os laços, minimizar os temores e promover situações de aprendizagem.

\section{CONCLUSÕES}

A aprendizagem é o princípio fundamental na educação e o anseio de toda comunidade escolar. Meta difícil de ser alcançada na atualidade, visto o desencadear de um novo fenômeno social, com reflexo dentro da unidade escolar: a violência. Em observação do quadro de resultados do Colégio Estadual Sesquicentenário, percebeu -se que a falta de paz provocou instabilidade emocional tanto em professores, quanto em alunos, fator determinante para um maior índice de reprovação e evasão escolar. Diante do quadro, foi necessário criar um projeto, com ações interventivas e preventivas, que viesse criar um ambiente de paz, a fim de garantir o direito de aprender. Nos olhares de Ducemara Benato 
(2014); Luana Santos e José Toniosso (2014); Raquel Cabral et al (2015); Michele Marchesan et al (2017); André Oliveira (2015); Elias Silva e Sueli Gonçalves (2015); Marcelo Pereira (2015); Sobreiro e Estrada (2016) Michele Marchesan et al (2017) é preciso criar um ambiente saudável e tranquilo para que possa acontecer aprendizagem.

O envolvimento da comunidade foi o passo determinante para a melhoria dos problemas da escola. A partir de um momento com os professores, foi criado um cronograma de ações com alunos, professores e funcionários. Assim, foi realizado: Seminário de Segurança Pública, promovido pelo Ministério Público, em parceria com a Faculdade UNIME; oficinas de conhecimento, promovido pela Universidade Estadual de Santa Cruz. Das atividades sugeridas pela SEC - BA, foram implementados os projetos estruturantes com a temática incentivando a promoção da paz, " o olhar sobre o outro": Festival Anual da Canção Estudantil, concurso Literário, Artes Visuais Estudantis; como ainda seminários, shows. Concurso locais, regionais e estaduais levaram alguns alunos desta escola a serem destaque na mídia televisiva e jornais da cidade; participação em olimpíadas da matemática, regional e nacional; jogos escolares e até participação de um aluno no concurso Parlamento Jovem em Brasília. Como também, obteve - se bons resultados em seleções para bolsista em Menor Aprendiz.

Elias Silva e Sueli Gonçalves (2015) comentam que,

\begin{abstract}
Uma gestão escolar participativa engloba os princípios da democrática quando defende que a educação está na coordenação de atitudes que afirmam a participação social no planejamento, execução e elaboração e execução de políticas educacionais. Essas medidas dentro da esfera educacional operam para a observação da permanência do aluno na escola e a ele é dada uma educação com qualidade social. (SILVA, e GONÇALVES, 2015, p.5)
\end{abstract}

As ações interventivas, quanto as preventivas, realizadas na unidade escolar, trouxeram resultados agradáveis: o que antes era conflito negativo, transformou - se em desempenho positivo. As ações pedagógicas pontuais tiraram a escola das páginas vermelhas da internet para a mídia educacional de crescimento. 
Gestão escolar e parceiros - elementos imprescindíveis na

promoção da paz no ambiente escolar, com vistas a aprendizagem

\section{REFERÊNCIAS}

ANTUNES, Celso. Novas Maneiras de Ensinar, Novas Formas de Aprender. Porto Alegre: Artimed, 2002.

BENATO, Dulcemara Terezinha. FAMÍLIA E Escola: uma relação de desafios. Paraná: Secretaria de Educação, 2014.

BANDURA, A.; AZZI, R. G.; POLYDORO, S. Teoria Social Cognitiva: conceitos básicos. Porto Alegre: Artmed, 2008.

BRUNER, Jerome S. Uma Nova Teoria da Aprendizagem. Rio de Janeiro: Bloch, 1976.

CABRAL, Raquel; GOTHARDO, Josiane; MURBACK, Lucas. A cultura da paz no contexto das relações públicas comunitárias e responsabilidade social. RAZÓN Y PALAVRA - Primeira Revista Eletrônica Iberoamérica Especializada em Comunicación. № 88, dezembro de 2014 a fevereiro de 2015.

Disponível em: https://repositorio.unesp.br/handle/11449/135509

Acesso em: 18.01.2019

CALLADO, Carlos Velásquez. Educação para a Paz: promovendo valores humanos na escola, através da educação física e jogos cooperativos. Tradução de Maria Rocio Bustius da Veiga Santos. São Paulo: Editoras Cooperação, 2004.

COLL, César. Aprendizagem Escolar e a Construção do Conhecimento. Porto Alegre: Artimed, 1994.

GARDNER, H. Inteligência: um conceito reformulado. Rio de Janeiro: Objetiva, 1999.

MARCHESAN, Michele Roos.; QUARTIERI, Marli Teresinha.; SCHUCK, Rogério José.; SCHWERTNER, Suzana Feldens. Os desafios da escola contemporânea: enunciações de uma professora da rede pública de educação. Lajedo- Rio Grande do Sul: Revista Thema 2017.

OLIVEIRA, André Luiz Regis de. Entre a escola e a família: nuances de um (des)encontro. Dissertação de Mestrado Dissertação apresentada como requisito parcial para obtenção do grau de Mestre pelo Programa de Pós-Graduação em Educação. Rio de Janeiro: PUC, 2015.

Disponível em: https://www.maxwell.vrac.puc-rio.br/25938/25938.PDF

Acesso em: 18.01.2019

OLIVEIRA, Gilberto Carvalho de. Estudos da paz: origens, desenvolvimentos e desafios críticos atuais. Belo Horizonte: Rev. Carta Inter., v. 12, n. 1, 2017.

PEREIRA, Marcelo Fernandes. Educação para a paz na filosofia de Emanuel Lévinas. Tese de Doutorado apresentada ao Programa de Pós- Graduação em Educação da Faculdade de Educação da Universidade Estadual de Campinas para obtenção do título de Doutor em Educação São Paulo: UNICAMP, 2015.

Disponível

http://repositorio.unicamp.br/bitstream/REPOSIP/322082/1/Pereira_MarceloFernandes_D.pdf

Acesso em: 18.01.2019

PIAGET, J. A Linguagem e o Pensamento da Criança. Tradução de Manoel Campos. Rio de Janeiro: Fundo da Cultura, 1959.

SACRISTÁN, J.G.; GÓMEZ, A.I. Pérez. Compreender e Transformar o Ensino. Porto Alegre: Artimed, 2000.

SANTOS, Luana Rocha.;TONIOSSO, José Pedro. A importância da relação escola-família. Bebedouro- São Paulo: Centro Universitário - UNIFAFIBE, 2014.

SEC - BA. Manual Orientador do Colegiado Escolar. Salvador, 2017.

Disponível em: file:///C:/Users/Genilda\%20Melo/Downloads/colegiado-portaria-no-1480-2017.pdf

Acesso em: 18.01.2019 
SILVA, Elias do Nascimento.; GONÇALVES, Sueli Silva da Mota. GESTÃo ESCOLAR PARTICIPATIVA: algumas inquietações. Semana Acadêmica.org., 2015.

Disponível em: https://semanaacademica.org.br/system/files/artigos/artigo_gestao.pdf

SOBREIRO, Albertina de Barros.; ESTRADA, Adrian Alvarez. Articulação entre os segmentos de Gestão da Escola: o Conselho Escolar em análise. Paraná: SEC-PA, 2016.

TANAJURA, Laudelino Luiz Castro.; BEZERRA, Ada Augusta Celestino. Pesquisa-Ação sob a ótica de René Barbie e Michel Thiollent: aproximações e especificidades metodológicas. Rev. Eletrônica Pesquiseduca, Santos, v. 07, n. 13, p.10-23, jan.-jun.. 2015.

Disponível em: https://www.google.com/search?source=hp\&ei=xTlCXLOfFOHD5OUPyLiusA8\&q=pesquisa+a\% Acesso em: 18.01.2019.

TOLEDO, Renata Ferraz de.; GIATTI, Leandro Luiz.; JACOBI, Pedro Roberto. A pesquisa-ação em estudos interdisciplinares: análise de critérios que só a prática pode revelar. Butucatu-São Paulo: Revista Interface - Comunicação, Saúde, Educação, 2014.

VYGOTSKY, L. S. A Formação Social da Mente. São Paulo: Martins Fontes, 1984.

(cc) EYY

Este trabalho está licenciado com uma Licença Creative Commons - Atribuição 4.0 Internacional. 